\title{
Effect of respiratory muscle strengthening on rowing performance
}

\author{
Angage Dilani Priyashanthi Perera', Anoja Ariyasinghe ${ }^{2}$, Anula Kariyawasam ${ }^{2}$ \\ ${ }^{1}$ Lecturer, Department of Physiotherapy, Faculty of Allied Health Sciences, General Sir John Kotelawala Defence \\ University, Sri Lanka, ${ }^{2}$ Senior Lecturer, Department of Physiology, Faculty of Medicine, University of Peradeniya, \\ Sri Lanka
}

Background: Respiratory muscle training (RMT) has been proposed as a beneficial means of improving respiratory muscle strength (RMS) and respiratory muscle fatigue (RMF) in athletes. Aims and Objective: The aim of this study was to determine the effects of a 12-week specific RMT program on the RMS, RMF and rowing ergometer performance in highly- trained rowers. Materials and Methods: Twenty professional rowers aged 20-35 years were recruited for the study during the competitive period and randomly grouped into an experimental $(n=11)$ or control $(n=9)$ group. Baseline measurements of maximal inspiratory and expiratory mouth pressures were obtained with a portable handheld mouth pressure meter while performance was assessed by $2000 \mathrm{~m}$ and $5000 \mathrm{~m}$ rowing ergometer machine. Subsequently rowers in the experimental group were prescribed a novel RMT program comprising of specific breathing and abdominal muscle exercises while the control group was prescribed a "general exercise program" for non- respiratory muscles for a 12-week period. RMF was assessed by calculating the difference between the pre-exercise and post-exercise mouth pressures. Results: Respiratory muscle strength improved overtime in the experimental and the control group following the respective training programs $(p<0.05)$ with the experimental group showing higher RMS and lower RMF. However, there were no statistically significant differences in RMS and RMF between the two groups $(P>0.05)$. More importantly, rowing ergometer performance improved significantly in the experimental group compared to the control $(p<0.01)$. Conclusion: The results suggest that the novel RMT program had a significant effect in improving rowing performance, although the effect on RMS and RMF was not significant.

Key words: Respiratory muscle strength; Respiratory muscle fatigue; Rowing ergometer performance
http://nepjol.info/index.php/AJMS DOI: 10.3126/ajms.v11i6.30084

E-ISSN: 2091-0576

P-ISSN: 2467-9100

Copyright (c) 2020 Asian Journal of Medical Sciences

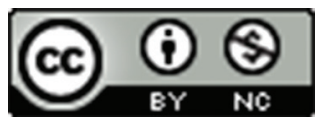

This work is licensed under a Creative Commons Attribution-NonCommercial 4.0 International License.

\section{INTRODUCTION}

The respiratory muscles, including the diaphragm, react to an increase in physical activity by increasing minute ventilation. ${ }^{1}$ This increase in ventilatory demands raises the work of breathing and increases the propensity for respiratory muscle fatigue (RMF), ${ }^{2}$ The occurrence of RMF leads to alterations in breathing patterns to facilitate and maintain the force-generating capacity of the inspiratory muscles. Studies have demonstrated that both the inspiratory and expiratory muscles are susceptible to fatigue and would impose limitations to exercise tolerance in healthy adults during high intensity sustained exercises ${ }^{3,4}$ and prolonged sub-maximal exercises. ${ }^{5}$

Harms, (2002) reported that respiratory muscles were susceptible to exercise-induced fatigue, due to the imbalance between the increasing metabolic demands of locomotor muscles and the higher demand on the respiratory muscles for increased gas exchange. ${ }^{2}$ During intense exercise, an increase in respiratory muscle demand for oxygen reduces the limb blood flow by diverting the blood flow from the limb muscles to the respiratory muscles, the metaboreflex. ${ }^{6,7}$ 
This accelerates the rate of limb muscle fatigue potentially limiting exercise tolerance. ${ }^{2}$

In the sport of rowing, 'extreme' demands are placed on the respiratory muscles as it is involved in; 1 . Increased ventilation 2. Maintaining structural stability and strengthening of the spine and other bony structures 3 . Generation and transmission of propulsive force during the rowing stroke, ${ }^{7}$ Therefore, during rowing, when work intensity increases, the diaphragm's role in ventilation takes preference over its role in postural stability. ${ }^{5}$ This may lead to an increased risk of injury due to spinal instability and a loss of postural control which would result in low performance.

Therefore, strengthening of the respiratory muscles especially the diaphragm would help to delay the onset of the metaboreflex, by reducing the blood flow demand by the respiratory muscles, ${ }^{8}$ increase the cardiac output to the leg muscles and thereby improving the performance. ${ }^{9,10}$

Respiratory muscle training (RMT) is a technique that can be used to improve the strength of the respiratory muscles. RMT consists of inspiratory muscle training (IMT) or expiratory muscle training (EMT) or a combination of both. RMT has been shown to improve respiratory muscle strength in different athletic groups such as marathon runners, ${ }^{11}$ triathlons, ${ }^{12}$ rowers, ${ }^{9}$ cyclists ${ }^{13}$ and swimmers ${ }^{14}$ in both western and developing countries.

There are many devices that are used for RMT such as Voluntary Isocapnic Hyperpnoea, Inspiratory flow resistive loading (IFRL) and Pressure threshold loading (PTL). As these are expensive and unavailable in many developing nations this study aimed at introducing a new protocol of RMT which comprised of specific breathing and abdominal exercises to strengthen the respiratory muscles.

\section{MATERIALS AND METHODS}

A case controlled randomized study was conducted in 20 male light weight rowers aged 20-35 years during the competitive period at the General Sir John Kotelawala Defence University, Ratmalana and Exercise and Sports Science laboratory, Department of Physiology, Faculty of Medicine, University of Peradeniya. Age (25.3 \pm 3.5 years $)$, body weight $(71.3 \pm 5.5 \mathrm{~kg})$ and height $(176.9 \pm 8.9 \mathrm{~cm})$ matched rowers were randomly divided into an experimental $(\mathrm{n}=11)$ and a control group $(\mathrm{n}=9)$. Healthy adult national male rowers and non-smokers were included in the study while smokers and those with respiratory illnesses or on medication for any other illness were excluded from the study.
The rowers were informed about the details of the research project, test procedure, risks and benefits. Written informed consent was taken from each subject prior to the administration of the questionnaire which included; demographic data, general information of the rowing sport, smoking history, duration and number of cigarettes per day/week/month), alcohol abuse, medical and surgical history and presence of injuries. Ethical Clearance was obtained from Ethics Review Committee, Faculty of Medicine, University of Peradeniya (2016/EC/52). This trial was retrospectively registered (UMIN000040345, 09/05/2020).

Prior to the commencement of the training program, baseline measurements and tests namely, respiratory muscle strength including maximal inspiratory (PImax) and maximal expiratory pressures (PEmax), 2000m and $5000 \mathrm{~m}$ rowing ergometer time trial were carried out on all 20 subjects. Respiratory muscle strength (RMS) which includes inspiratory muscle strength (IMS) and expiratory muscle strength (EMS) were measured by maximal inspiratory mouth pressure (PImax) and maximal expiratory mouth pressures (PEmax) respectively using a mouth pressure meter (Micro MPM, Micro Medical Ltd., Kent, United Kingdom; Precision Medical MPM, UK). All measurements were taken using a flanged mouthpiece in an upright standing position. The flanged mouthpiece was placed in the mouth of the subject with the lips making a tight seal around it. Nose clips were worn to occlude the nares while performing the manoeuvre. Participants were given careful instructions prior to the test and encouraged throughout the procedure. To assess Maximal Inspiratory Pressure (PImax), the subjects were instructed to inhale fully with a sharp, forceful effort which was maintained for a minimum of $\sim 2$ seconds while Maximal Expiratory Pressure (PEmax) was evaluated with the subjects requested to inhale maximally up to total lung capacity (TLC) and then to exhale forcibly and maximally. ${ }^{15}$ The test distance of $2000 \mathrm{~m}$ and $5000 \mathrm{~m}$ are commonly used to monitor rowing training and performance. The concept II, (Nottingham, UK) ergometer machine and stopwatch were used for the test and the time spent on the rowing ergometer machine was assessed. After a warm-up of 10 minutes duration, the drag factor was set at which the rower was to be tested. The stopwatch was used to measure the time duration to complete the 2000 meter and 5000-meter distance.

Thereafter, rowers in the experimental group were requested to follow a new protocol of "respiratory muscles training (RMT) program" for 7 days per week for 12 weeks period. This RMT included a warm-up session, flexibility training, inspiratory and expiratory muscle strength training programs and warm-down sessions. The flexibility training included stretching of the chest and trunk muscles 
by introducing full body stretches and lateral stretches which was repeated more than 30 times. ${ }^{16}$ The inspiratory muscle training program used different breathing exercises including diaphragmatic re-education, profound (deep) inspiration and inspiratory hiccups. ${ }^{17}$ These exercises mainly targeted strengthening of the diaphragm, external intercostals muscles and other accessory inspiratory muscles. Each technique was repeated 30 times with rest intervals between them. In the present study, abdominal muscles strengthening and endurance exercises namely; Isometric Side Bridge and Curl-ups ${ }^{16}$ were introduced in the expiratory muscle training program. A full description of all the components of the RMT program is included as Additional file 1.

The rowers in the control group were recommended a "general exercise program" for 7 days per week for 12 weeks period. This included a warm-up and warm down sessions (similar to intervention group), flexibility training and strength training programs for non-respiratory muscles. The flexibility training included the biceps stretching and triceps stretching. ${ }^{16}$ These exercises were repeated 10 times for both arms. In the control group, strength training exercises were included as follows: Biceps curls, Triceps curls, Hamstring curls and Quadriceps strengthening (Straight Leg raises). ${ }^{16}$ Additional file 2 includes a full description of general exercise program. Both programs were introduced in addition to the routine exercise schedule followed during the competition season. During the training programs, all participants in the experimental and the control groups were requested to maintain a detailed physical activity-training schedule and an "Exercise program training diary" in order to monitor training adherence. The respiratory muscle training program and the general exercise program were conducted for 7 days per week for 12 weeks after which assessment of the respiratory muscle strength, and ergometer performance were repeated.

Respiratory muscle fatigue (RMF) was also assessed using the mouth pressure meter. PImax or PEmax have been shown to be reliable measures of inspiratory and expiratory muscle fatigue. ${ }^{18}$ Inspiratory muscle fatigue (IMF) and expiratory muscle fatigue (EMS) were determined by calculating the difference between the pre-exercise and post-exercise mouth pressures. Pre-exercise (Pre-Ex) testing was done prior to the introduction of the respective training programs in both groups while post-exercise (Post-Ex) measurements were carried out at the end of 12-week training programs. Data was entered and validated in a (Statistical Package for Social Sciences (SPSS) version 17.0) database. The descriptive statistics were calculated for demographic data and respiratory muscle strength in both the experimental and the control group. Paired sample t test was used to compare variables before and after the exercise programs in the experimental and the control group. The independent sample $t$ test was used to compare the variables between the experimental group and the control group. Statistical analysis was conducted at a $95 \%$ confidence interval, and $\mathrm{p}<0.05$ was considered statistically significant.

\section{RESULTS}

Respiratory muscle strength namely Inspiratory muscle strength (IMS) and expiratory muscle strength (EMS) was assessed by measuring maximal inspiratory mouth pressure (PImax) and maximum expiratory mouth pressure (PEmax) in both, the control and experimental groups before and after introducing the non- RMT and RMT programs respectively are shown in Table 1 . Inspiratory muscle strength (PImax) improved by $22.5 \%$ in the experimental group, while an $11.0 \%$ improvement was seen in the control group after the respective exercise programs. The improvement was highly significant $(\mathrm{p}<0.01)$ in the experimental group compared to the control which was significant after the respective exercise programs. Significantly greater improvement of expiratory muscle strength (PEmax), $18.3 \%$ vs $15.9 \%$ was seen in the experimental group than the control group after the respective exercise programs $(p<0.01)$. However, when comparing PImax and PEmax after the exercise programs no significant difference was seen between the experimental and the control group ( $\mathrm{p}>0.05)$.

Table 2 shows the effect of non-RMT and RMT program on inspiratory muscle fatigue (IMF) and expiratory muscle fatigue (EMF) in both the control and the experimental group respectively. Inspiratory muscle fatigue was calculated as the mean difference between pre-training Peak

\begin{tabular}{|c|c|c|c|c|c|c|}
\hline \multirow[t]{2}{*}{ Respiratory muscle strength } & \multicolumn{3}{|c|}{ Control group } & \multicolumn{3}{|c|}{ Experimental group } \\
\hline & Pre Mean \pm SD & Post Mean \pm SD & $\mathrm{p}$ value & Pre Mean $\pm S D$ & Post Mean \pm SD & $p$ value \\
\hline PImax $(\mathrm{mmHg})$ & $114.2+18.1$ & $136.8+26.1$ & $0.01^{* *}$ & $109.4+33.0$ & $134.0+36.7$ & $0.001^{* *}$ \\
\hline PEmax (mmHg) & $144.1+22.6$ & $167.6+27.7$ & $0.03^{* *}$ & $158.3+37.8$ & $187.3+45.4$ & $0.001^{* *}$ \\
\hline
\end{tabular}

PImax: Peak Inspiratory Mouth Pressure, PEmax: Peak Expiratory Mouth Pressure, SD - Standard deviation, * $p<0.05-$ Significant, **p< $0.01-$ Highly Significant 
Inspiratory Mouth Pressure (Pre-training PImax) and post training Peak Inspiratory Mouth Pressure (Post training PImax) while EMF was calculated as the mean difference between pre-training Peak Expiratory Mouth Pressure (Pre-training PEmax) and post training Peak Expiratory Mouth Pressure (Post training PEmax). Both IMF and EMF were higher in the control group compared with the experimental group, but it was not significant ( $\mathrm{p}>0.05)$.

The $2000 \mathrm{~m}$ and $5000 \mathrm{~m}$ rowing ergometer time trial performance tests were assessed before (pre) and after (post) the exercise programs in the control and the experimental group as shown in Figure 1 and Figure 2 respectively. There was a significant reduction in both $2000 \mathrm{~m}$ and $5000 \mathrm{~m}$ ergometer performance time in the experimental group $(p<0.05)$ while the control group showed no significant

\begin{tabular}{|c|c|c|c|}
\hline \multirow{2}{*}{$\begin{array}{l}\text { Respiratory } \\
\text { muscle fatigue }\end{array}$} & \multicolumn{2}{|c|}{ Mean \pm SD } & \multirow[t]{2}{*}{$P$ value } \\
\hline & Control group & $\begin{array}{l}\text { Experimental } \\
\text { group }\end{array}$ & \\
\hline IMF (mmHg) & $-20.66 \pm 20.49$ & $-25.36 \pm 14.96$ & 0.58 \\
\hline EMF (mmHg) & $-29.00 \pm 28.39$ & $-31.81 \pm 14.42$ & 0.79 \\
\hline
\end{tabular}

IMF: Inspiratory Muscle Fatigue, EMF: Expiratory Muscle Fatigue, SD - Standard deviation, * $p<0.05$ - Significant

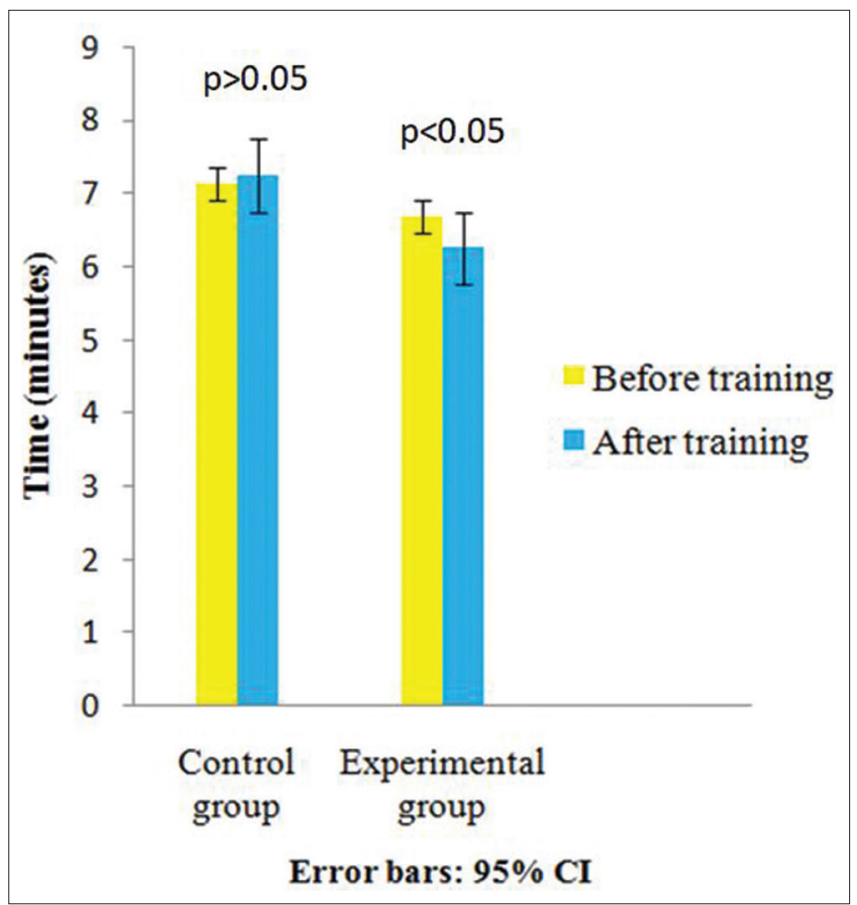

Figure 1: $2000 \mathrm{~m}$ time trial test before and after the exercise programs of the control and the experimental group. $2000 \mathrm{~m}$ rowing ergometer performance significantly improved in the experimental group $(p=0.001)$ while the control group $(\mathrm{p}=0.06)$ did not show significant improvement at the end of 12-week respective training program. Confident interval $(\mathrm{Cl})$ reduction. Both $2000 \mathrm{~m}$ and $5000 \mathrm{~m}$ ergometer performance were compared between control and experimental group after the 12-week training programs (Figure 3 and Figure 4). It was found that there was a significant difference $(p<0.05)$ between experimental and control group in both $2000 \mathrm{~m}$ and

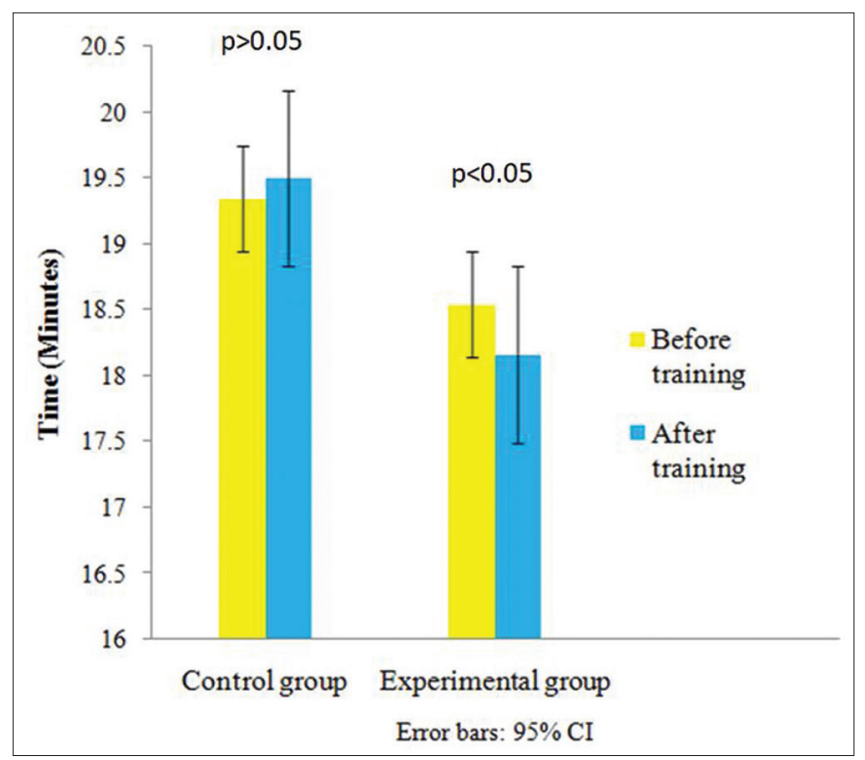

Figure 2: $5000 \mathrm{~m}$ time trial test before and after the exercise programs of the control and the experimental group. $5000 \mathrm{~m}$ rowing ergometer performance significantly improved in the experimental group $(p=0.04)$ while the control group $(p=0.73)$ did not show significant improvement at the end of 12-week respective training program. Confident interval $(\mathrm{Cl})$

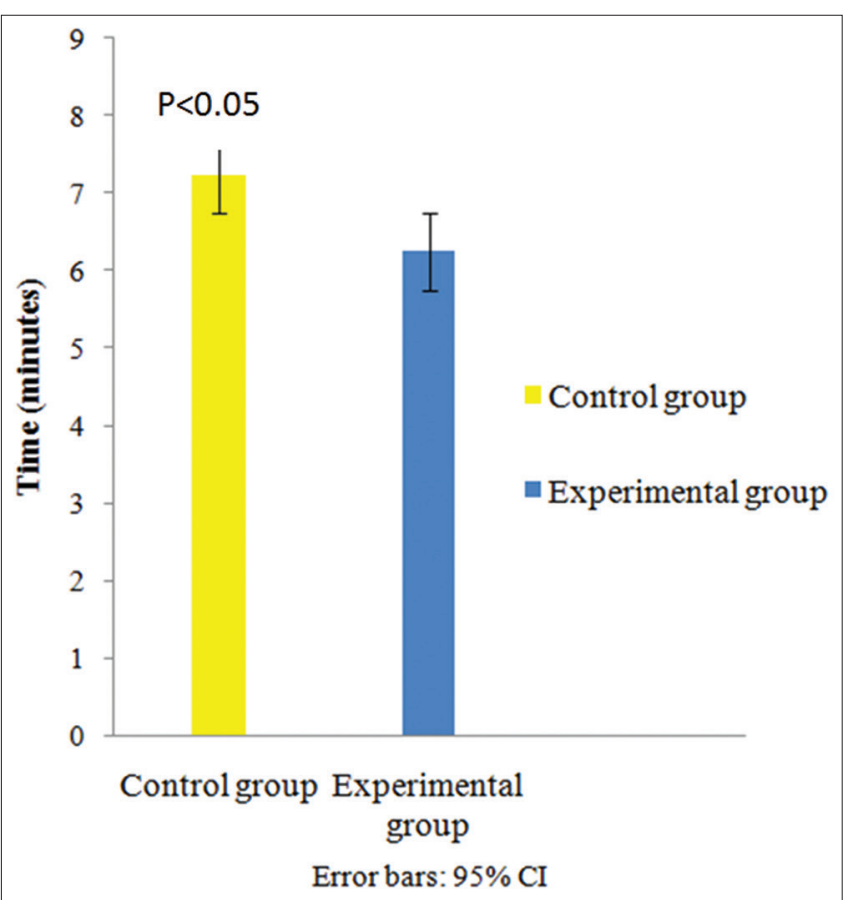

Figure 3: Comparison of $2000 \mathrm{~m}$ time trial test between the control and the experimental groups after the RMT program. There was a significant difference $(p=0.001)$ between experimental and control group in $2000 \mathrm{~m}$ ergometre time trial test after specific 12-week RMT program. Confident interval $(\mathrm{Cl})$. 
$5000 \mathrm{~m}$ ergometer time trial test after the exercise programs with the experimental group having a lower ergometer timing.

The relationship between respiratory muscle strength and ergometer performance in the control $(n=9)$ and the experimental group $(n=11)$ was shown in Table 3. The RMS and ergometer performance (both 2000m and $5000 \mathrm{~m})$ correlated negatively, but it was not significant in both groups ( $\mathrm{p}>0.05)$.

\section{DISCUSSION}

A vast number of studies have been done globally to assess the effect of Respiratory muscle training (RMT) in healthy,

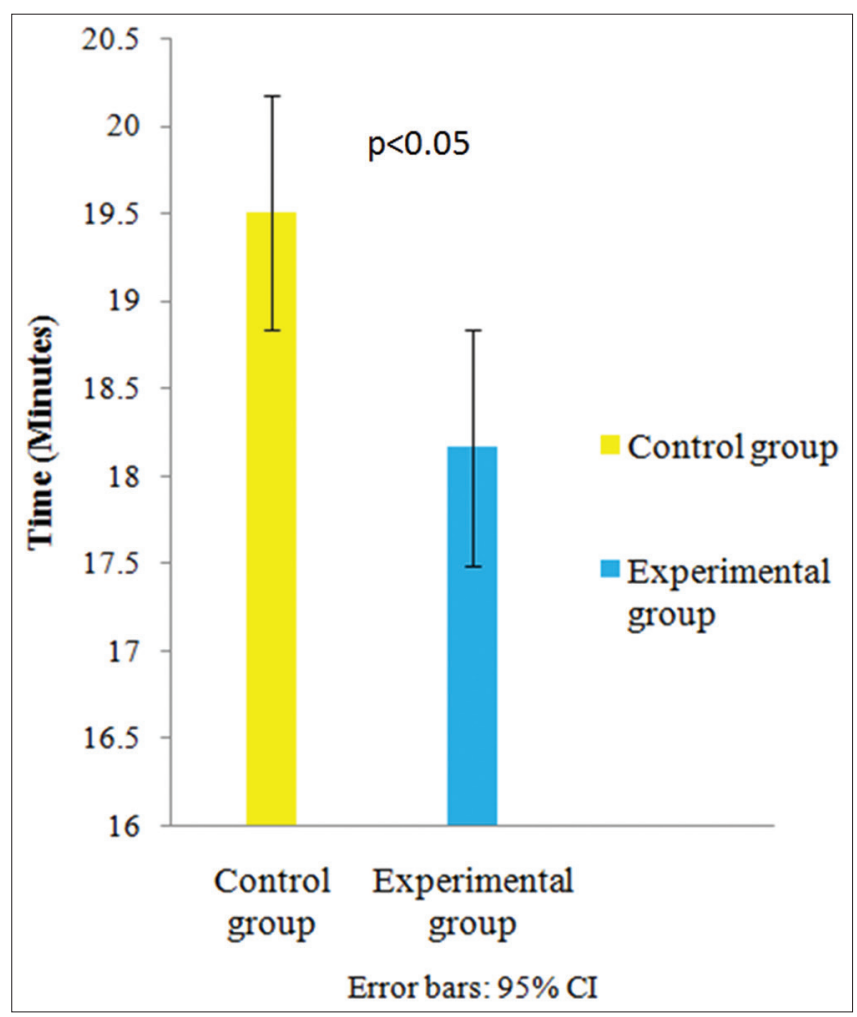

Figure 4: Comparisons of $5000 \mathrm{~m}$ time trial test between the contro and the experimental group after the exercise programs. There was a significant difference $(p=0.001)$ between experimental and control group in $5000 \mathrm{~m}$ ergometre time trial test after specific 12-week RMT program. Confident interval $(\mathrm{Cl})$ clinical and athletic populations. Many use different RMT devices to strengthen the respiratory muscles. This novel RMT program introduced in the present study used series of breathing techniques and exercises to increase the strength of the respiratory muscles and thereby improve the performance of Sri Lankan rowers.

Studies have shown that highly trained rowers have greater respiratory muscle pressures compared to normal healthy subjects of similar age and height. ${ }^{19}$ In the present study, there was a significant improvement in inspiratory muscle strength (PImax) and expiratory muscle strength (PEmax) following the respective training programs in both groups $(\mathrm{p}<0.05)$ overtime. The expiratory muscle strength was higher in the experimental group (18.3\%) compared to the control. However, no significant difference was observed between the two groups ( $p>0.05)$. Another study showed an improvement of $28.0 \%$ following RMT with the RMT device. ${ }^{20}$ Similar findings were observed in a study which showed that PImax improved in pre and post-exercise values in the control and the experimental groups and between the two groups. ' The improvement in PImax in the experimental group compares favorably with similar studies that have observed increases from $8 \%$ to $45 \%$ in PImax following resistive loading device. ${ }^{21}$ But, in contrast, some studies demonstrated an improvement in PImax only in the experimental group., ${ }^{9} 22$ However, Donnelly in 1991 has mentioned that there were no ergogenic benefits for male rowers performing RMT as their respiratory muscle strength may be sufficient to protect them from the inspiratory muscle fatigue. ${ }^{23}$

The increase in respiratory muscle strength is similar to the resistance and endurance training of the limb muscles or skeletal muscles with adaptations in muscle structure and function. This leads to an increase in strength, power and endurance of the diaphragm and accessory inspiratory muscles. ${ }^{24}$ Wilson has reported that similar to the skeletal muscles strength training, respiratory muscles strength training will show growth of predominantly type II fibre and while endurance training results in growth of type I fibre growth and RMT has been shown to increase both strength and endurance. ${ }^{25}$

Table 3: The relationship between respiratory muscle strength and ergometer performance in the control group $(n=9)$ and the experimental group $(n=11)$

\begin{tabular}{|c|c|c|c|c|c|c|c|c|}
\hline \multirow{2}{*}{$\begin{array}{l}\text { Respiratory } \\
\text { muscle } \\
\text { strength }\end{array}$} & \multicolumn{4}{|c|}{ Control group } & \multicolumn{4}{|c|}{ Experimental group } \\
\hline & \multicolumn{2}{|c|}{$\begin{array}{l}2000 m \text { ergometer } \\
\text { performance }\end{array}$} & \multicolumn{2}{|c|}{$\begin{array}{l}5000 \mathrm{~m} \text { ergometer } \\
\text { performance }\end{array}$} & \multicolumn{2}{|c|}{$\begin{array}{l}2000 m \text { ergometer } \\
\text { performance }\end{array}$} & \multicolumn{2}{|c|}{$\begin{array}{l}5000 \mathrm{~m} \text { ergometer } \\
\text { performance }\end{array}$} \\
\hline PImax (IMS) & -0.52 & 0.15 & -0.30 & 0.42 & -0.06 & 0.85 & -0.25 & 0.45 \\
\hline PEmax (EMS) & -0.06 & 0.87 & -0.62 & 0.07 & -0.34 & 0.31 & -0.13 & 0.71 \\
\hline
\end{tabular}

[IMS - Inspiratory muscle strength; EMS - Expiratory muscle strength; $r=$ Correlation coefficient; ${ }^{*} p<0.05$ - Significant; ${ }^{* *} p<0.01$ - Highly Significant] 
The respiratory muscles are vulnerable to exercise-induced fatigue during high intensity exercise due to the competition between increasing metabolic demands of the locomotor muscles and the associated increase in work of breathing by the respiratory muscles. ${ }^{26}$ It has been suggested that rowers having improved PImax and PEmax prevents them from developing inspiratory muscle fatigue (IMF) ${ }^{23}$ Although the exact mechanism by which RMF occurs is still unclear it has been suggested that RMT may help to overcome this by strengthening the respiratory muscles and reducing the demand for higher blood circulation to the respiratory muscles. In addition, RMT has been shown to reduce blood lactate concentration and sympathetic activation. ${ }^{9}$ This is important in delaying the occurrence of the metaboreflex which is important in improving exercise performance. ${ }^{26}$ In the present study, both IMF and EMF were lower in the experimental group compared to the control group, but there was no significant difference in both IMF and EMF between the two groups. This was consistent with the observation of several studies which showed that inspiratory muscle training increased inspiratory muscle strength, delayed IMF during exhaustive exercise, and improved maximal performance significantly. ${ }^{27}$ Volianitis has shown that RMT in lightweight oarswomen produced significant increases in PImax, decreased IMF, and improved rowing performance during a 6-minute all-out of effort and $5000 \mathrm{~m}$ race..$^{28}$ Some studies have suggested that even cardiovascular exercise (aerobic exercise) training protects athletes from the effects of RMF.,29 This means that whole-body endurance training for long periods could enhance respiratory muscle performance and reduce RMF. This could be the reason why it was observed that there was an increase in RMS even in the control group of our study although it was lower than the experimental group.

Many RMT research have used 'time trials' as a key outcome measure of exercise performance. ${ }^{28,29}$ In the present study, there was a significant improvement $(p<0.05)$ in the time trial in both the $2000 \mathrm{~m}$ (Figure 3) and $5000 \mathrm{~m}$ (Figure 4) ergometer performance in the experimental group compared to the control group after their respective training programs.

The results of the present study are consistent with the findings of previous studies, ${ }^{17}$ who revealed that there was a significant improvement in rowing performance in the experimental group after RMT. Volianitis (2001) was the first to investigate the effect of RMT in well-trained female rowers, and observed that there was a 1.9\% increase in the distance covered in the 6 Minutes All Out of effort (6MAO) test and the time to complete the $5 \mathrm{~km}$ time trial decreased by $2.2 \%$ compared to the control group. ${ }^{28}$ In contrast, a study by Riganas ${ }^{17}$ on national Greek female rowing squad observed a significant increase in both
Pre-and post-Exercise PImax following IMT but no change in $2 \mathrm{~km}$ rowing ergometer performance. Therefore, the benefits associated with RMT on rowing performance remains indecisive. ${ }^{17,30}$

Several studies have observed a positive impact on sports performance of inspiratory muscle training in healthy, untrained and trained subjects in comparison to the expiratory muscle training. ${ }^{9}$ Inspiratory muscle training has been shown to improve exercise capacity during short term high intensity and sub-maximal cycling ${ }^{28,31}$ and repeated sprint exercise. ${ }^{32}$

When considering the relationship between respiratory muscle strength (RMS) and performance it was observed that rowers with higher IMS and EMS performed better with lower timings in both $2000 \mathrm{~m}$ and $5000 \mathrm{~m}$ ergometer tests in the present study, although it was not significant $(\mathrm{p}>0.05)$ (Table 3). This shows that improving RMS has an important role in the enhancing exercise performance. This compares well with a study which showed a strong negative correlation between PEmax and the time spent in the rowing ergometer machine. ${ }^{33}$ This study also suggested that EMS is associated more with exercise performance than IMS. In contrast, some studies have suggested that even with an increase in RMS no change has been observed in exercise performance especially in athletes or cyclists. ${ }^{34,35}$

\section{CONCLUSION}

It was observed, that both the control and the experimental group developed significantly higher IMS and EMS after engaging in their respective training programs while IMF and EMF were lower in the experimental group compared to the control group. However, there was no significant difference in RMS or the development of RMF between two groups. More importantly, rowers who followed the RMT program performed better in both $2000 \mathrm{~m}$ and $5000 \mathrm{~m}$ rowing ergometer tests compared to the control group. Therefore, it can be concluded that applying the RMT program in the training schedules of rowers resulted in improving both $2000 \mathrm{~m}$ and $5000 \mathrm{~m}$ rowing ergometer performance.

\section{Limitation and future scope of the study}

The major limiting factor of the current RMT exercise program was that this training schedule did not include major resistant training programs for the respiratory muscles during inhalation and exhalation for adaptation of the respiratory muscles to occur. In contrast, many RMT devices require the participant to inspire or expire against a fixed flow resistance load which could be controlled. Therefore, to improve the effects of this program, it is 
recommended that special resistant balloons, example a thera band to generate a resistant load. In all forms of resistance training, not only should the intensity of the exercise be increased, but the overall volume and duration should also be changed. Training at a higher volume, by increasing the number of repetitions, might produce more favourable metabolic changes in the respiratory muscles. Further investigations are also warranted for posturespecific RMT to enhance ventilatory functions in the different rowing postures as the group that received RMT was shown to have better ventilatory parameters than the control.

\section{ACKNOWLEDGMENT}

The authors would like to acknowledge all the rowers who participated in the study for their fullest cooperation and contribution. We are grateful for the support we have received during data collection from the technical staff of the Exercise and Sports Science laboratory, Department of Physiology, Faculty of Medicine, University of Peradeniya and Gymnasium, General Sir John Kotelawala Defence University. Further, we would like to thank Mr. P. Dias, Senior Lecturer, University of Sri Jayewardenepura who assisted us in statistical analysis of data.

\section{REFERENCES}

1. Powers SK and Shanely RA. Exercise induced changes in diaphragmatic bioenergetic and antioxidant capacity. Exercise Sport Science Review. 2002;30(2): 69-74.

https://doi.org/10.1097/00003677-200204000-00005

2. Harms CA, Wetter T, St. Croix CM, Pegelow DF and Dempsey JA. Effects of respiratory muscle work on exercise performance. Journal of Applied Physiology. 2000; 89: 131-138. https://doi.org/10.1152/jappl.2000.89.1.131

3. Coast JR, Clifford PS, Henrich TW, Stray-Gundersen J and Johnson JR. Maximal inspiratory pressure following maximal exercise in trained and untrained subjects. Medicine and Science in Sports and Exercise. 1990; 22:811-815. https://doi.org/10.1249/00005768-199012000-00013

4. Mador MJ, Magalang UJ, Rodis A and Kufel TJ. Diaphragmatic fatigue after exercise in healthy human subjects. American Review of Respiratory Disease. 1993;148:1571-1575.

https://doi.org/10.1164/ajrccm/148.6_Pt_1.1571

5. Johnson BD, Babcock MA, Suman OE and Dempsey JA. Exercise-induced diaphragmatic fatigue in healthy humans. Journal of Physiology. 1993; 460:385-405.

https://doi.org/10.1113/jphysiol.1993.sp019477

6. Harms CA, Babcock MA, McClaren SR, Pegelow DF, Nickele GA, Nelson WB, et al. Respiratory muscle work compromises leg blood flow during maximal exercise. Journal of Applied Physiology. 1997; 825: 1573-1583. https://doi.org/10.1152/jappl.1997.82.5.1573

7. Mahler DA, Shuhart CR, Brew E and Stukel TA. Ventilatory responses and entrainment of breathing during rowing.Medicine and Science in Sports and Exercise.1991; 23:186-193. https://doi.org/10.1249/00005768-199102000-00007

8. O'Kroy JA and Coast R. Effects of flow and resistive training on respiratory muscle endurance and strength. Respiration. 1993; 60: 279-283.

https://doi.org/10.1159/000196216

9. Klusiewicz A, Borkowski L, Zdanowicz R, Boros $\mathrm{P}$ and Wesolowski S. The inspiratory muscle training in elite rowers. Journal of Sports Medicine and Physical Fitness. 2008; 48: 279-284.

10. Griffiths LA and McConnell AK. The influence of inspiratory and expiratory muscle training upon rowing performance. Eur J Appl Physiol. 2007; 99 (5):457-66. https://doi.org/10.1007/s00421-006-0367-6

11. Ross E, Middleton N, Shave R, George K and McConnell A. Changes in respiratory muscle and lung function following marathon running in man. Journal of Sports Science, 2008; 26: 1295-1301.

https://doi.org/10.1080/02640410802104904

12. Ker JA and Schultz CM. Respiratory muscle fatigue after an ultramarathon measured as inspiratory task failure. Int J Sports Med. 1996; 17: 493-496.

https://doi.org/10.1055/s-2007-972884

13. Romer LM, McConnell AK and Jones DA. Effects of inspiratory muscle training on time-trial performance in trained cyclists. Journal of Sports Science.2002; 20:547-562.

https://doi.org/10.1080/026404102760000053

14. Kilding AE, Brown $S$ and McConnell AK. Inspiratory muscle training improves 100 and $200 \mathrm{~m}$ swimming performance. European Journal of Applied Physiology. 2010; 108: 505-511. https://doi.org/10.1007/s00421-009-1228-x

15. Green M, Road J, Sieck GC and Similowski T. Tests of respiratory muscle strength. American Thoracic Society / European Respiratory Society on respiratory muscle testing. American Journal of Respiratory and Critical Care Medicine. 2002; 166:528-524.

https://doi.org/10.1164/rccm.166.4.518

16. Fahey TD, Insel P and Roth W. Fit \& Well Core Concepts and LABS in Physical Fitness and Wellness. 2005; 6- 186.

17. Porter SB. Management of respiratory disease, fifteen edition; Tidy's Physiotherapy. 2013; 83-127.

https://doi.org/10.1016/B978-0-7020-4344-4.00006-7

18. Supinski GS, Fitting GW and Bellemare F. Assessment of respiratory muscle fatigue. American Thoracic Society/ European Respiratory Society on respiratory muscle testing. American Journal of Respiratory and Critical Care Medicine. 2002; 166: 571-579.

https://doi.org/10.1164/rccm.166.4.518

19. Shephard R. Science and medicine of rowing: a review. Journal of Sport Sciences. 1998; 16: 603-620.

https://doi.org/10.1080/026404198366416

20. Riganas C, Vrabas IS, Christoulas K and Mandroukas K. Specific inspiratory muscle training does not improve performance or VO2max levels in well-trained rowers. Journal of Sports Medicine and Physical Fitness. 2008; 48:285-292.

21. Mickleborough TD, Nichols T, Lindley MR, Chatham $K$ and lonescu AA. Inspiratory flow resistive loading improves respiratory muscle function and endurance capacity in recreational runners. Scandanavian Journal of Medicine and Science in Sports. 2009; 1-11. https://doi.org/10.1111/j.1600-0838.2009.00951.x

22. Sonnetti DA, Wetter TJ, Pegelow DF and Dempsey JA. Effects of respiratory muscle training versus placebo on 
endurance exercise performance. Respiration Physiology. 2001; 127:185-199.

https://doi.org/10.1016/S0034-5687(01)00250-X

23. Donnelly PM, Ellis ER, Keating JM, Keena VA, Woolcock AJ and Bye PTP. Lung function of rowers. The Australian Journal of Science and Medicine in Sport, 1991; 232:42-46.

24. McConnell AK and Romer L. Respiratory muscle training in healthy humans: resolving the controversy. International Journal of Sports Medicine. 2004; 25: 284-293.

https://doi.org/10.1055/s-2004-815827

25. Wilson JM, Loenneke JP, Wilson GJ, Zourdos MC and Kim JS. The effects of endurance, strength, and power training on muscle fiber type shifting. J Strength Cond Res.2012; 26 (6):1724-1729. https://doi.org/10.1519/JSC.0b013e318234eb6f

26. Mador MJ and Acevedo FA. Effect of respiratory muscle fatigue on subsequent exercise performance. American Physiological Society. 1991; 705:2059-2065.

https://doi.org/10.1152/jappl.1991.70.5.2059

27. Segizbaeva MO, Timofeev NN, Donina ZHA, Kuryanovich EN and Aleksandrova NP. Effects of inspiratory muscle training on resistance to fatigue of respiratory muscles during exhaustive exercise. Adv Exp Med Biol. 2015; 840:35-43.

https://doi.org/10.1007/5584_2014_20

28. Volianitis S, McConnell AK, Koutedakis Y, McNaughton L, Backx $\mathrm{K}$ and Jones DA. Inspiratory muscle training improves rowing performance. Medicine and Science in Sports and Exercise. 2001; 33: 803-809.

https://doi.org/10.1097/00005768-200105000-00020

29. Mickleborough TD, Stager JM, Chatham K, Lindley MR and Ionescu AA. Pulmonary adaptations to swim and inspiratory muscle training. European Journal of Applied Physiology.2008;
103: 635-646.

https://doi.org/10.1007/s00421-008-0759-x

30. Vrabas IS, Riganas CS, Benaxides NI and Mandroukas K. Does inspiratory muscle training reduce exercise-induced arterial hypoxemia in female rowers? Medicine and Science in Sports and Exercise. 2007; 39:5

https://doi.org/10.1249/01.mss.0000273537.14368.40

31. Caine MP and McConnell AK. The inspiratory muscles can be trained differently to increase strength or endurance using a pressure threshold, inspiratory muscle training device. European Respiratory Journal. 1998; 12:58-59.

32. Tong TK, Fu FH, Chung PK, Eston R, Lu K, Quach B, et al. The effect of inspiratory muscle training on high-intensity, intermittent running performance to exhaustion. Applied Physiology, Nutrition and Metabolism.2008; 33:671-681. https://doi.org/10.1139/H08-050

33. Sugiura H, Ohta K, Minatani S, Tanoue H, Kokubo A, Kanada Y, et al. Relationship between Respiratory Muscle Strength and xrcis Tolerance. Journal of Physical Science. 2009; 21: 393-397. https://doi.org/10.1589/jpts.21.393

34. Williams JS, Wongsathikum J, Boon SM and Acevedo EO. Inspiratory muscle training fails to improve endurance capacity in athletes. Medicine and Science in Sports and Exercise. 2002; 34(7): 1194-1198. https://doi.org/10.1097/00005768-200207000-00022

35. Downey AE, Chenoweth LM, Townsend DK, Ranum JD, Ferguson CS and Harms CA. Effects of inspiratory muscle training on exercise responses in normoxia and hypoxia. Respiratory Physiology and Neurobiology. 2007; 156 (2): 137-146.

https://doi.org/10.1016/j.resp.2006.08.006

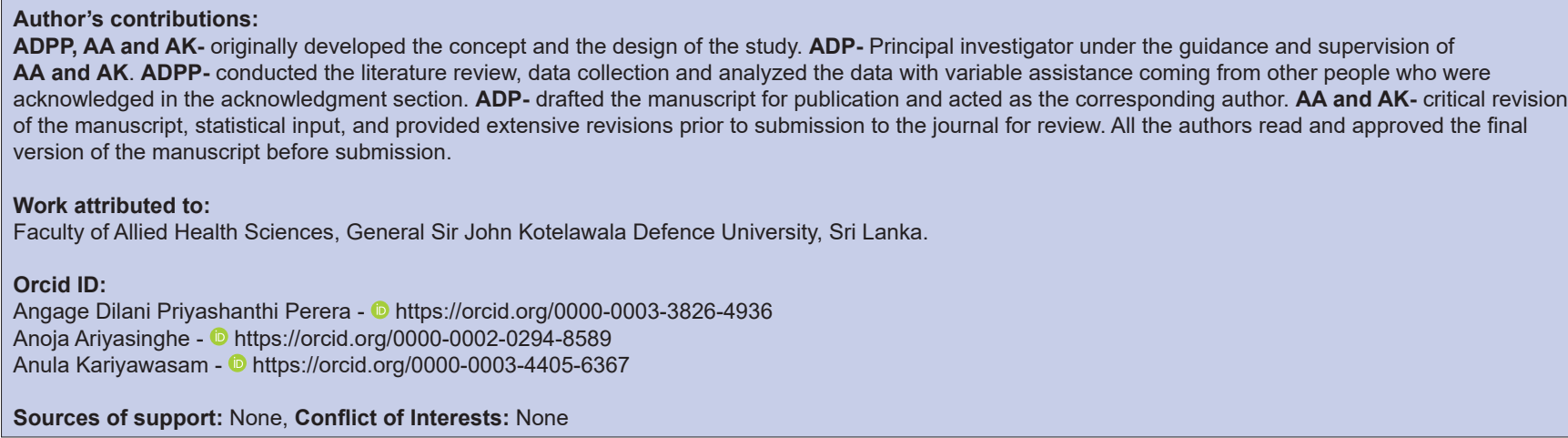

